\title{
Metallurgical Effects of Niobium and Molybdenum on Heat-Affected Zone Toughness in Low-Carbon Steel
}

\author{
Hardy Mohrbacher ${ }^{1,2}$ \\ 1 NiobelCon bvba, 2970 Schilde, Belgium \\ 2 Department of Materials MTM, Leuven University (KU Leuven), 3001 Leuven, Belgium; hm@niobelcon.net; \\ Tel.: +32-3-484-5206
}

Received: 7 April 2019; Accepted: 29 April 2019; Published: 5 May 2019

\begin{abstract}
Modern weldable high strength steel grades are typically based on low-carbon alloy concepts using microalloying for obtaining a good strength-toughness balance. Such steel grades having a yield strength in the range of 420 to $690 \mathrm{MPa}$ are very commonly used in pipelines, heavy vehicles, shipbuilding and general structural applications. Thermomechanical processing during hot rolling combined with accelerated cooling is an established means of producing such steel grades. Considering the alloying concepts, the use of niobium and molybdenum, and in selected cases boron, is very efficient to achieve high strength and good toughness. However, all targeted applications of such high strength steels involve extensive welding. Thus, heat affected zone properties are of particular importance. The present paper investigates the effects of $\mathrm{Nb}, \mathrm{Mo}$ and Ti on the heat affected zone properties. Variations of the Mn and Si contents are considered as well. Additionally, the influence of post-weld heat treatment in the coarse-grained heat-affected zone (HAZ) is considered. In this approach, HAZ subzones were generated using laboratory weld cycle simulations in combination with systematic variation of alloying elements to scrutinize and interpret their specific effects. The results indicate that $\mathrm{Mo}$ and $\mathrm{Nb}$, when alloyed in the typical range, provide excellent HAZ toughness and guarantee sufficiently low ductile-to-brittle transition temperature. An alloy combination of $\mathrm{Nb}$, Mo and Ti improves performance under hot deformation conditions and toughness after post-weld heat treatment.
\end{abstract}

Keywords: welding simulation; heat-affected zone; post-weld heat treatment; high-strength steel; microalloying; solubility; precipitation; solute drag; abnormal grain coarsening; hot ductility

\section{Introduction}

The development of steel for use in pipeline, structural and automotive applications has seen a remarkable evolution since the late 1960s [1]. The increasing demands in terms of strength and toughness in general and weldability, in particular, have led to the design of alloys with reduced carbon content (Figure 1a). Nowadays, steel of 700 MPa yield strength (grade 100) is achievable with a maximum carbon content of 0.05 percent [2]. Reducing carbon increases upper shelf energy and lowers the ductile-to-brittle transition temperature (Figure $1 \mathrm{~b}$ ). The required strength is provided by either microstructural refinement, precipitation hardening or dislocation hardening. Typically a combination of these mechanisms is used. Since grain refinement is the only mechanism simultaneously improving strength and toughness (Figure 1b), it should be always applied in the first place before employing other strengthening mechanisms. Microstructural refinement is efficiently achieved by niobium micro-alloying in combination with thermo-mechanical controlled processing (TMCP). This approach of producing high strength low alloy (HSLA) steel containing below 0.1 percent carbon and niobium micro-alloying between 0.02 and 0.04 percent is covering a wide portfolio of applications in the 
yield strength range of 300 to $500 \mathrm{MPa}$. Typically, the carbon content is between 0.06 and 0.09 percent for many of these steel grades resulting in a ferritic-pearlitic or pearlite-reduced ferritic microstructure. The trend of further reducing the carbon content is reasoned by improving upper shelf toughness and reducing ductile-to-brittle-transition temperature (DBTT). Besides, avoiding the peritectic range has clear benefits with regards to slab surface quality. In the 1980s, Hulka and Gray [3] proposed an extraordinary alloy concept using particularly low carbon content in combination with a high niobium micro-alloy addition of 0.1 percent.

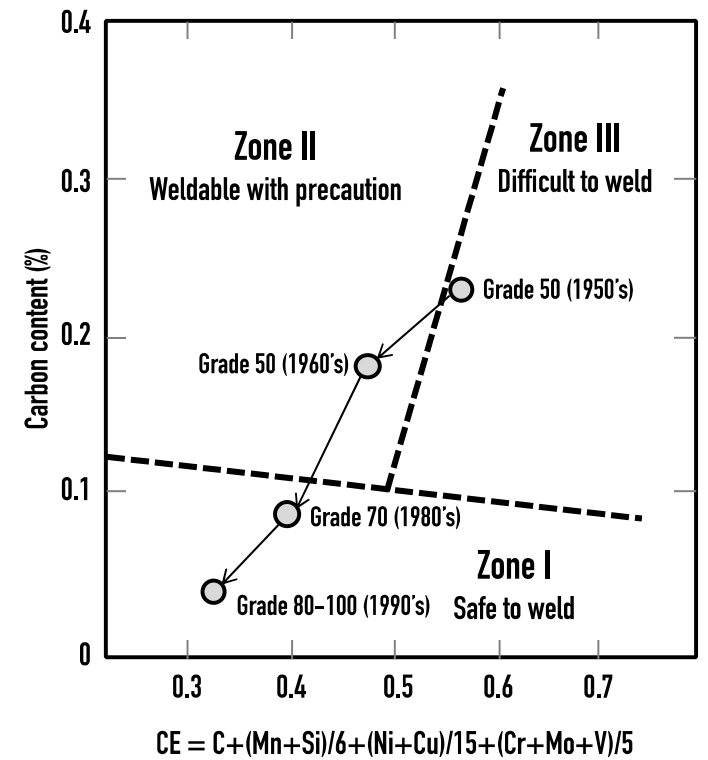

(a)

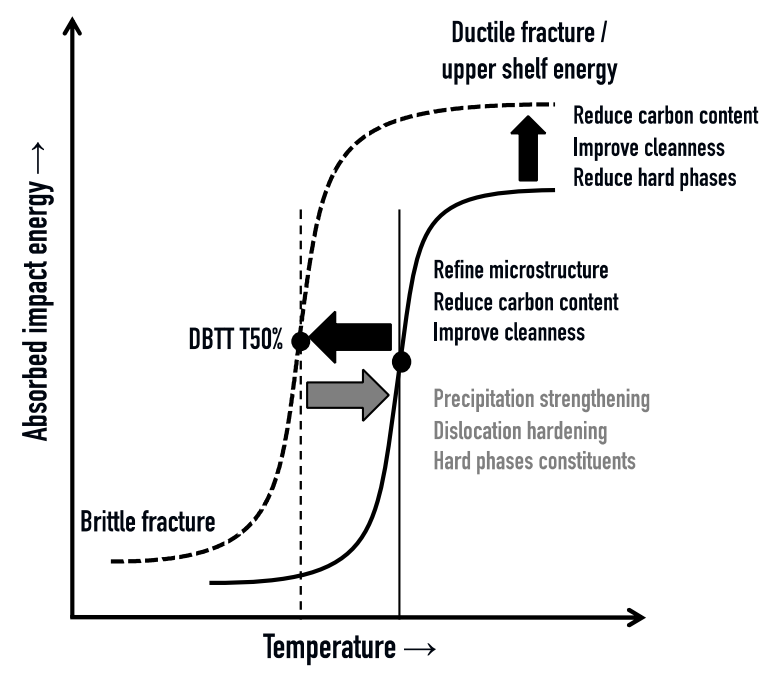

(b)

Figure 1. Design criteria for weldable high strength steels: (a) The Graville diagram classifying weldability of steels and historical evolution of chemical composition represented by the carbon equivalent (CE) in high strength steels; (b) ductile-to-brittle transition (DBTT) behavior and criteria influencing the toughness behavior in steel.

The intrinsic benefits of modern low-carbon alloy concepts are a particularly high upper shelf toughness and very low DBTT. The microstructure of such alloys is nearly pearlite-free ferrite or by using increased cooling rate, acicular ferritic. The high recrystallization stop temperature of such high-niobium alloyed steel principally widens the processing window for TMCP rolling and enables higher production throughput, especially on hot strip mills. On the other hand, it allows producing ferritic-bainitic microstructure even by air-cooling after finish rolling. Fine-tuning of the original low-carbon high-niobium alloyed steel concept using chromium and molybdenum as co-alloying elements has opened a wide range of interesting applications for producing steel in the range of 460 to $700 \mathrm{MPa}$ yield strength. These can be found in pipe as well as automotive applications. Considering structural applications, some traditional specifications do not allow the use of such innovative alloy concepts since the niobium content is often restricted although several studies indicated that concerns may not be justified [4-6]. Historically, the limitation of niobium addition relates to concerns about weldability and low heat affected zone (HAZ) toughness. Thereby, it is not accounted for that higher niobium additions are typically used in extra-low-carbon steels. Previous investigations applying industrial welding processes to such steels revealed that heat-affected zone toughness is not negatively affected by niobium additions in the range from 0.02 to $0.11 \%[7,8]$. The present study will focus on the metallurgical effects and microstructural changes occurring in the individual sub-zones of the heat-affected zone in extra-low-carbon steel $(0.035 \% \mathrm{C})$ primarily considering the effects of niobium and molybdenum alloying. The effects of titanium and silicon alloying are additionally addressed. Post-weld heat treatment (PWHT) is used in selected applications for weld stress relaxation in thicker 
gaged components fabricated from high strength steel [9]. Micro-alloyed steels can show embrittlement by such treatment. Thus, simulations of PWHT are performed in this study to investigate the embrittlement sensitivity of these steels in the coarse-grained heat affected zone.

\section{Materials and Methods}

\subsection{Definition of the Test Materials}

Low-carbon $(0.035 \%)$ steels with a systematic variation of alloying elements were designed as specified in Table 1. Such alloys are being used for pipe steels with high requirements regarding toughness and sour gas resistance. Several of these alloy compositions are in actual industrial use for pipe related strip and plate products. Thereby, lower-Mn and Mo-free variants cover X60-X65 grades whereas the higher alloyed variants are being used for $\mathrm{X} 70$ and $\mathrm{X} 80$ grades ( $\mathrm{X}$ refers to minimum yield strength, number in ksi).

Table 1. Variation of alloy compositions in mass \% subjected to heat-affected zone (HAZ) simulations (symbols refer to all subsequent diagrams).

\begin{tabular}{|c|c|c|c|c|c|c|c|c|}
\hline Alloy & Symbol & C & $\mathbf{S i}$ & Mn & $\mathrm{Cr}$ & $\mathbf{T i}$ & Mo & $\begin{array}{c}\mathrm{Nb} \\
\text { (varied in all alloys) }\end{array}$ \\
\hline $\mathrm{V} 1$ & $\diamond$ & \multirow{6}{*}{0.035} & \multirow{5}{*}{0.30} & \multirow{2}{*}{1.45} & \multirow{6}{*}{0.20} & 0.00 & \multirow{3}{*}{$\mathbf{0 . 0 0}$} & \multirow{6}{*}{$\begin{array}{l}\text { a: } 0.00 \\
\text { b: } 0.02 \\
\text { c: } 0.05 \\
\text { d: } 0.10\end{array}$} \\
\hline V2 & 0 & & & & & & & \\
\hline V3 & $\triangle$ & & & \multirow{4}{*}{1.90} & & 0.015 & & \\
\hline V4 & $\Delta$ & & & & & & \multirow{3}{*}{0.15} & \\
\hline V5 & 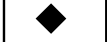 & & & & & 0.00 & & \\
\hline V6 & $\square$ & & 0.10 & & & 0.015 & & \\
\hline
\end{tabular}

All alloy variants (V1-V6) were produced as $300 \mathrm{~kg}$ laboratory melts in an induction furnace. Each sub-variant (a-d) was cast into a $75 \mathrm{~kg}$ ingot and the niobium level was increased in the remaining melt to the next level. The ingots were forged into square bars $(75 \times 75 \mathrm{~mm})$ at $1200^{\circ} \mathrm{C}$. These bars were subsequently cut into segments, which were subjected to the following rolling schedule:

- Reheating temperature: $1150^{\circ} \mathrm{C}+/-10^{\circ} \mathrm{C}$.

- Rouging rolling in four passes to $35 \mathrm{~mm}$.

- Thermo-mechanical rolling to $13 \mathrm{~mm}$ in five passes.

- Final rolling temperature: $850^{\circ} \mathrm{C}+/-20^{\circ} \mathrm{C}$

- Water cooling or in selected case air cooling.

The produced steel plates were characterized by tensile testing and the resulting values are displayed in Figure 2a. The alloy variants cover a yield strength $\left(R_{\mathrm{p} 0.2}\right)$ range from 350 to $600 \mathrm{MPa}$. Thereby the increase of the $\mathrm{Nb}$ level in each variant clearly relates to a strength increase, amounting to $50-160 \mathrm{MPa}$ when adding $0.1 \% \mathrm{Nb}$. The tensile strength correlates well with the yield strength indicating an average yield-to-tensile ratio (YTR) of 0.78 . The toughness of each alloy variant was characterized by standard Charpy V-notch testing using a $10 \times 10 \mathrm{~mm}$ sample size (acc. to DIN 10045). The upper-shelf toughness of these steel alloys scatters around $200 \mathrm{~J}$. This level is relatively low for such low-carbon steel. An industrially produced reference material (X65) having nearly the composition of variant V2-c showed an upper-shelf toughness of $370 \mathrm{~J}$ in comparative tests. The ductile-to-brittle transition temperature, i.e., the temperature at which $50 \%$ of the upper-shelf energy is reached (DBTT $\mathrm{T} 50 \%$, Figure $1 \mathrm{~b})$ is also lower in the industrial material $\left(-125^{\circ} \mathrm{C}\right)$ as compared to the laboratory alloy $\mathrm{V} 2-\mathrm{c}\left(-85^{\circ} \mathrm{C}\right)$. The differences in the toughness behavior are due to a lower cleanness of the laboratory 
melts, which were produced under non-vacuum conditions. However, the comparison between the various laboratory melts allows identifying the toughness influence of the alloying elements relative to each other. The DBTT results of all laboratory steels are shown in Figure 2b. It is apparent that the DBTT in each alloy system decreases with increasing $\mathrm{Nb}$ addition, irrespective of the strength level of the base alloy. This beneficial behavior is related to the pronounced microstructural refinement induced by $\mathrm{Nb}$ micro-alloying. The two data points marked as "PF" in Figure $2 \mathrm{~b}$ have a mostly polygonal ferritic $(\mathrm{PF})$ microstructure in contrast to the acicular ferritic microstructure of all other alloys.

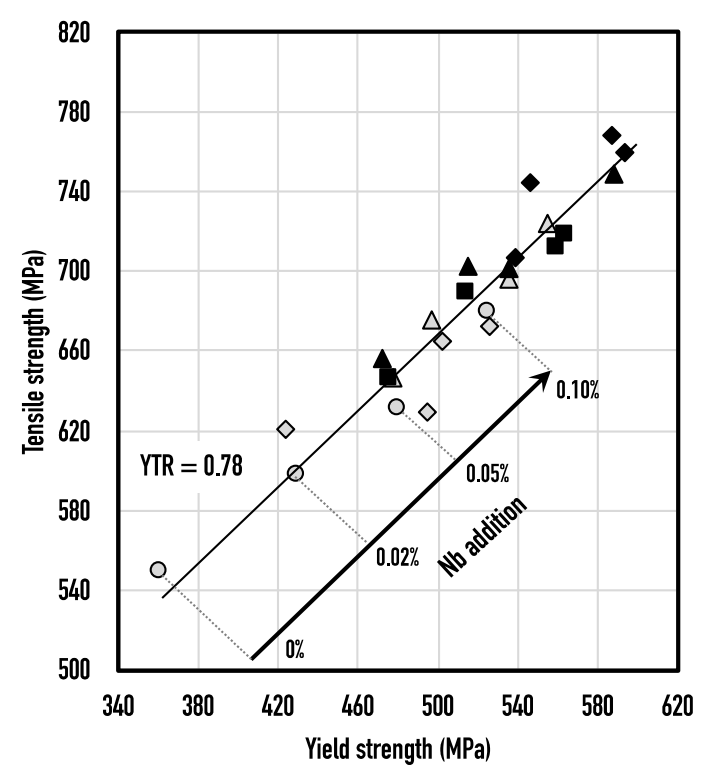

(a)

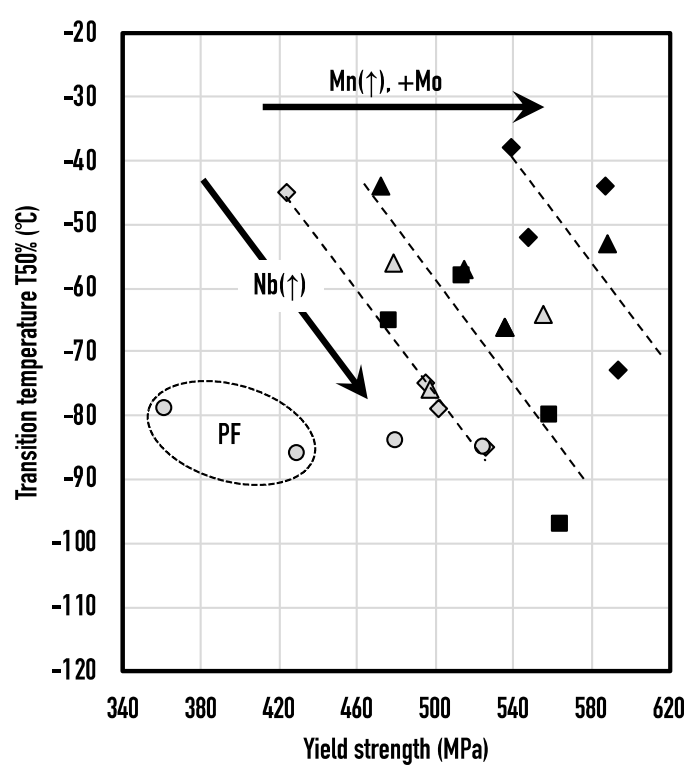

(b)

Figure 2. Properties of the as-rolled materials: (a) Relationship of yield strength $\left(\mathrm{R}_{\mathrm{p} 0.2}\right)$ and tensile strength; (b) ductile-to-brittle transition temperature (50\%) determined by Charpy testing (PF: polygonal ferrite matrix, all other acicular ferrite matrices).

The base material microstructure and the refining effect of $\mathrm{Nb}$ are demonstrated by light optical micrographs in Figure 3. The $\mathrm{Nb}$-free base alloy V2-a reveals a polygonal ferritic microstructure (Figure 3a) containing carbon-rich phases such as degenerated pearlite (dark contrast) and a small amount of MA-phase (white islands). The microstructure of the $\mathrm{Nb}$-alloyed variant (V2-d) is dominated by fine-grained acicular ferrite. The addition of molybdenum to $\mathrm{Nb}$-free steel (V4-a) prevents the formation of polygonal ferrite and promotes a coarse-grained acicular ferritic microstructure (Figure 3c). Adding niobium to this alloy (V4-d) results in remarkable refinement of this acicular ferritic microstructure (Figure 3d). 


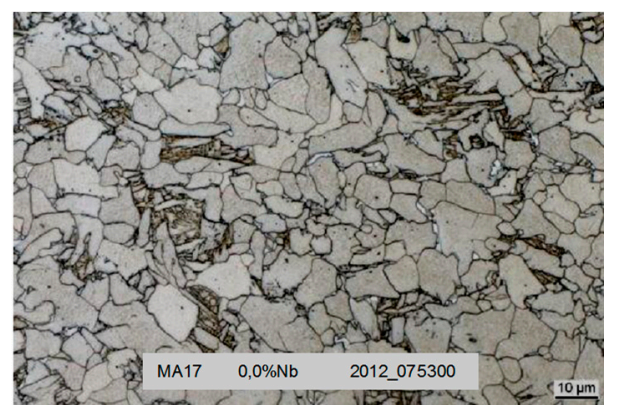

(a)

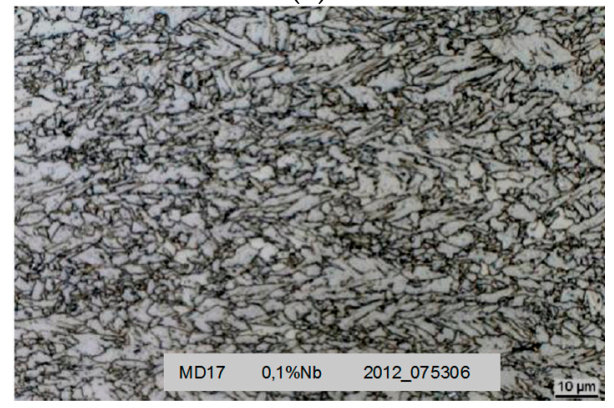

(c)

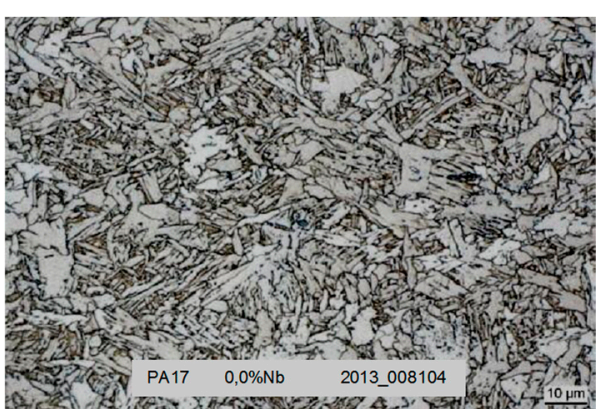

(b)

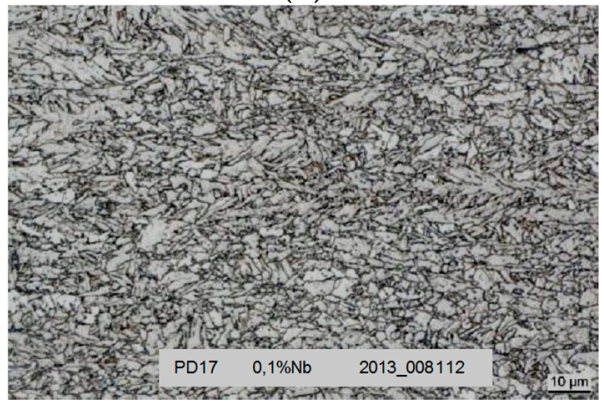

(d)

Figure 3. Light optical micrographs (Le Pera etching) of the as-rolled materials: (a) V2-a (polygonal ferrite); (b) V2-d (mostly acicular ferrite); (c) V4-a (coarse acicular ferrite); (d) V4-d (fine acicular ferrite).

\subsection{Heat Affected Zone Simulation and Characterization}

The simulation of heat affected sub-zones was performed in a HAZ simulator (Vatron GmbH, Linz, Austria) using electric current for fast conductive heating to a peak temperature and an air-water mixture applied via four coaxially positioned nozzles for rapid cooling (Figure 4). A thermocouple fixed in the center of the sample provides feedback for the time-temperature control software (Lab-View). The samples for this test were machined from the laboratory-rolled $13 \mathrm{~mm}$ thick plates to a size of $10 \times$ $10 \times 95 \mathrm{~mm}^{3}$. These samples were instrumented with thermocouples and clamped into the electrodes leaving a free length of $60 \mathrm{~mm}$. This setup results in a sample volume of approximately $10 \times 10 \times$ $15 \mathrm{~mm}^{3}$ having a homogeneous heat affected microstructure. For hardness measurements (Vickers HV10) and metallographic analysis, the homogeneous HAZ was cut from the sample. For tensile testing, the bar was machined to a round standard tensile sample $(Q 10 \mathrm{~mm})$ with the homogeneous zone being centered in the gage length. Likewise, Charpy test bars of $10 \times 10 \mathrm{~mm}^{2}$ were machined having the V-notch centered to the homogeneous HAZ.

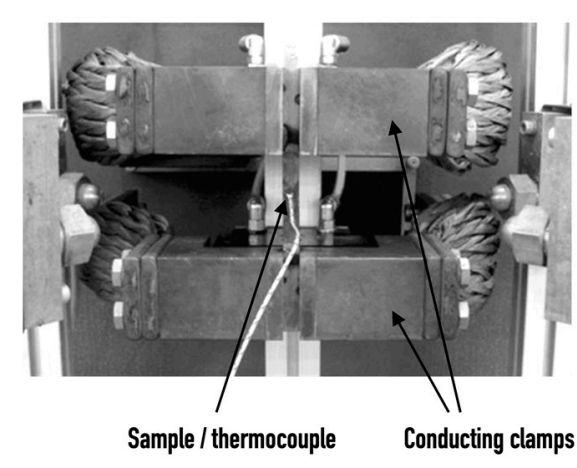

(a)

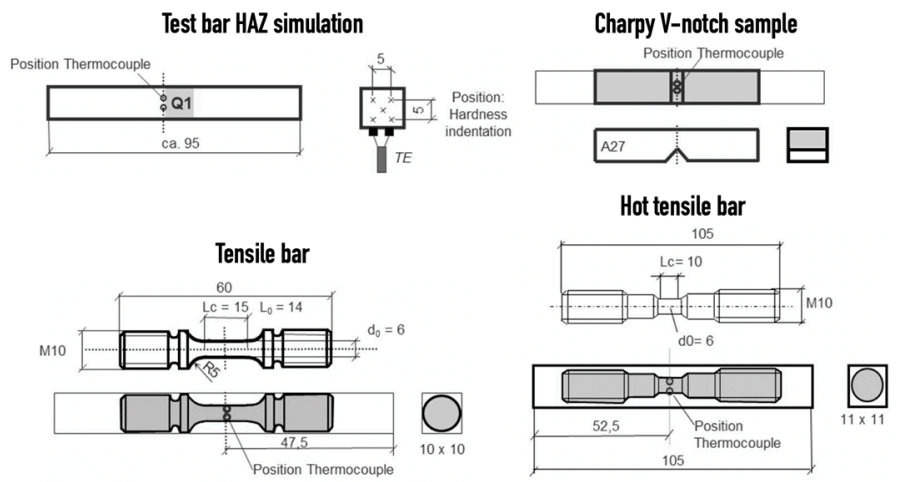

(b)

Figure 4. (a) Setup for HAZ simulation and (b) sample geometries for mechanical testing. 
HAZ simulations were performed for the inter-critical zone (ICZ), i.e., the peak temperature being in the ferrite-austenite two-phase region, and for the coarse-grained zone (CGZ) using a peak temperature of $1300{ }^{\circ} \mathrm{C}$. For defining the peak temperature in the ICZ, dilatometer tests were done identifying the transformation points in the up-heat cycle at a heating rate of $600 \mathrm{~K} / \mathrm{s}$. The peak temperature should be set to in between the maximum transformation points $\mathrm{A}_{\mathrm{clp}}$ and $\mathrm{A}_{\mathrm{c} 3 \mathrm{p}}$. This condition was for all alloys fulfilled for a peak temperature of $900{ }^{\circ} \mathrm{C}$. The fine-grained zone requires a peak temperature being approximately $50^{\circ} \mathrm{C}$ above the transformation finish temperature $\mathrm{A}_{\mathrm{c} 3 \mathrm{e}}$. This condition was fulfilled at $1100{ }^{\circ} \mathrm{C}$ for the current alloys. For obtaining the characteristic tensile properties across the entire HAZ, samples were produced at peak temperatures of $300,600,800,900,1100$ and $1300^{\circ} \mathrm{C}$ and machined into tensile bars. The heating rate was always set to around $600 \mathrm{~K} / \mathrm{s}$ and the cooling rate was adjusted to yield an $800-500{ }^{\circ} \mathrm{C}$ temperature interval $\left(\Delta \mathrm{T}_{8 / 5}\right)$ of $25 \mathrm{~s}$ corresponding to typical values obtained by submerged arc welding in practice.

\subsection{Post-Weld Heat Treatment Simulation and Characterization}

For simulating the material behavior under post-weld heat treatment (PWHT), the coarse-grained microstructure was produced in a first step using a peak temperature of $1300^{\circ} \mathrm{C}$ as described above. Machined round tensile bars from this CGZ material were then subjected to hot tensile tests in the temperature range of 300 to $620^{\circ} \mathrm{C}$. Particularly the reduction of area (RA) measured under the given tensile temperature is taken as an indicator for relaxation embrittlement sensitivity. In industrial applications, PWHT is typically performed in the temperature range of 500 to $600{ }^{\circ} \mathrm{C}$ [9]. To characterize the material behavior after such a treatment in detail, CGZ samples were heat treated at $560{ }^{\circ} \mathrm{C}$ for $30 \mathrm{~min}$. Thereafter samples of all alloy variants were characterized in the same fashion as described for the HAZ simulations providing hardness, tensile test and toughness data.

\section{Results}

The experimental program as described in paragraph 2 delivered a large amount of data of which only part is reported here allowing to draw relevant conclusions on the effect of alloying elements such as niobium, molybdenum, manganese and silicon. Regarding toughness, the upper-shelf energy values measured in the ICZ and CGZ are similar to those found in the base material. Again, the industrial reference steel $\mathrm{X} 65$ shows in comparison to laboratory material V2-c much higher upper-shelf energies and lower DBTT values in the ICZ and CGZ. A thorough analysis of all toughness data revealed that the DBTT T50\% data exhibit the strongest correlation with the alloy variations. Therefore, only DBTT $\mathrm{T} 50 \%$ data are considered in the following analysis.

\subsection{Mechanical Characteristics of HAZ Sub-Zones}

Figure 5 indicates the change in mechanical characteristics for alloy V3 after exposure to peak temperatures in the range of 300 to $1300^{\circ} \mathrm{C}$. The hardness measurements indicate significant softening in the ICZ, i.e., after heating to $900{ }^{\circ} \mathrm{C}$ peak temperature. The softening is most pronounced for the $\mathrm{Nb}$-free steel losing $72 \mathrm{HV} 10$ compared to the base material. For the alloy with the highest $\mathrm{Nb}$ addition, the hardness drop is only $36 \mathrm{HV} 10$. In the CGZ, the behavior is similar yet less strong. Here the Nb-free alloy is softening by $52 \mathrm{HV} 10$ while the highest $\mathrm{Nb}$-alloyed variant shows no hardness loss. Already the smallest $\mathrm{Nb}$ addition of $0.02 \%$ reveals a significant softening resistance in both, ICZ and CGZ. The measured HV10 hardness relates quite well to the measured tensile strength by a factor of 3.2.

Instead of reporting yield and tensile strength data as a function of the peak temperature, it is more interesting looking at the evolution of the yield-to-tensile ratio (YTR). The latter is more conclusive with regard to microstructural changes. In Figure 5 the YTR evolution is plotted as an interpolation of the data obtained at $300,600,800,900,1100$ and $1300{ }^{\circ} \mathrm{C}$ for the $\mathrm{Nb}$-free and $0.1 \% \mathrm{Nb}$ containing alloy V3. Generally, the YTR of the $0.1 \% \mathrm{Nb}$ steel is consistently higher than that of the $\mathrm{Nb}$-free steel. The YTR increases form its base material when the peak temperature is raised to sub-critical values $\left(<\mathrm{A}_{\mathrm{clp}}\right)$. A maximum of the YTR appears between 600 and $800{ }^{\circ} \mathrm{C}$, which is more pronounced and 
appears at a somewhat higher temperature in the $0.1 \% \mathrm{Nb}$ alloy as compared to the $\mathrm{Nb}$-free alloy. In the latter, the YTR shows a sharp drop to a pronounced minimum value of 0.54 in the ICZ. The YTR of the $0.1 \% \mathrm{Nb}$ alloy, on the contrary, drops only to 0.75 in the ICZ. In the CGZ, the YTR increases from its minimum value in the ICZ to a level between 0.7 and 0.8 .

The increase of the YTR in the sub-critical temperature range of $600-800{ }^{\circ} \mathrm{C}$ is typically related to tempering and precipitation phenomena. Tempering of hard carbon-enriched phases in the original material reduces primarily the tensile strength while precipitation of solute micro-alloys primarily increases the yield strength. Particularly the precipitation behavior of $\mathrm{Nb}$ will be discussed in paragraph 4 in more detail. The very low YTR of the $\mathrm{Nb}$-free steel in the ICZ is a clear indicator for a microstructure with dual-phase character. The dispersion of the martensitic phase in a soft matrix provides a low yield and high tensile strength. Such dual-phase steels are deliberately produced by annealing in the inter-critical temperature range followed by fast cooling. Metallographic analysis using Le Pera etchant reveals the presence of martensite in the ICZ material. In the optical microscope, these phases appear with a white or brownish color.

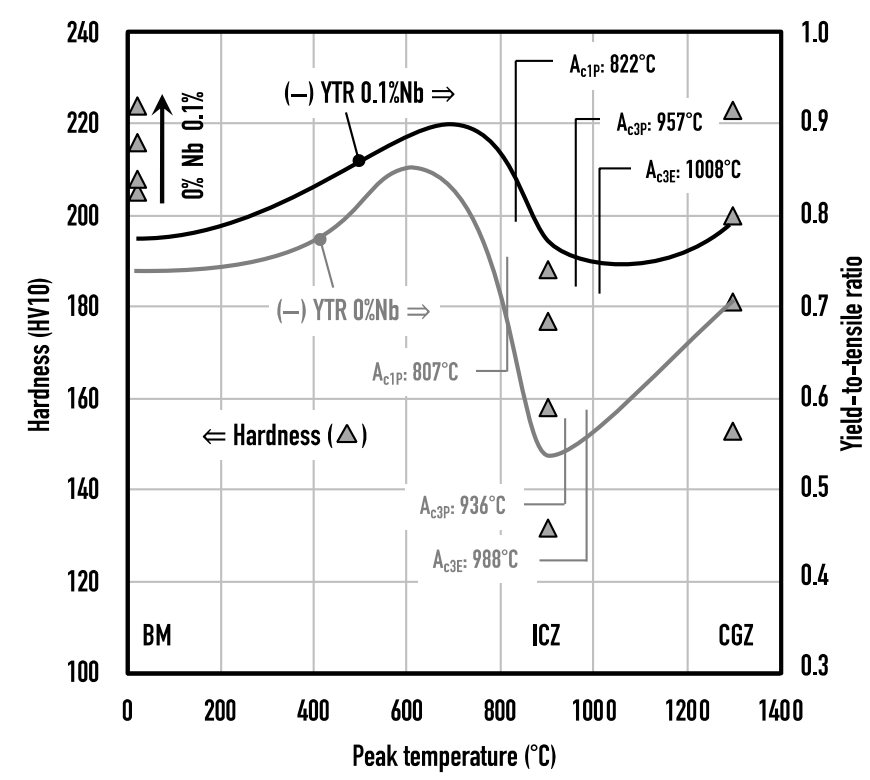

(a)

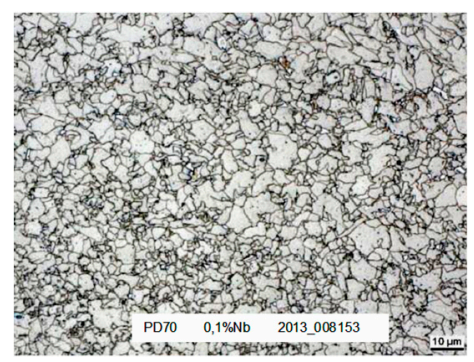

(c)

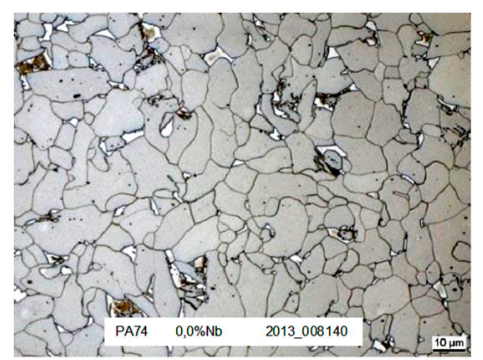

(b)

Figure 5. Heat-affected zone simulation of alloy V3: (a) Evolution of hardness and yield-to-tensile ratio (YTR) and measured transformation temperatures during up-heating; (b) microstructure in the inter-critical zone (ICZ) of the Nb-free alloy V3-a; (c) microstructure of alloy V3-d containing $0.10 \% \mathrm{Nb}$ (etching with Le Pera agent).

Figure $5 \mathrm{~b}$ shows the presence of a small fraction of martensite islands dispersed in a fully recrystallized polygonal ferrite matrix of the $\mathrm{Nb}$-free steel. The original acicular ferritic microstructure of the base material has completely disappeared. In the $0.1 \% \mathrm{Nb}$-alloyed steel (Figure $5 \mathrm{c}$ ) the ICZ microstructure also appears fully recrystallized. However, the polygonal ferrite grains are much finer than those in the $\mathrm{Nb}$-free alloy. The amount of martensite islands in the microstructure is almost negligible. Grain refinement has a stronger effect (Hall-Petch relationship) on the yield strength than on the tensile strength. Thus, with decreasing grain size the YTR increases. The strength of the refined polygonal ferrite is however still lower compared to the acicular ferritic base material as the sub-structure within the grain is lost due to recrystallization.

Adding molybdenum in alloy V4 shows qualitatively the same mechanical behavior as in alloy V3 (Figure 6a) and similar effects of niobium. However, the hardness scattering range between $\mathrm{Nb}$-free and $0.1 \% \mathrm{Nb}$ containing alloys in the ICZ and CGZ is less wide. Particularly the Nb-free alloy softens 
less, which is a known effect caused by Mo. The $0.1 \% \mathrm{Nb}$ steel, on the contrary, shows a greater hardness loss in the CGZ compared to the base material. This can indicate less precipitation hardening by niobium in the CGZ. The YTR indicates less softening in the sub-critical zone of the $\mathrm{Nb}$-free alloy while the dual phase character in the ICZ (YTR $=0.54$ ) is identical to alloy V3. The YTR in the CGZ is somewhat lower as in alloy $\mathrm{V} 3$, regardless of the $\mathrm{Nb}$ content.

Reducing the silicon content in alloy V6 leads to somewhat more softening of the $\mathrm{Nb}$-free alloy in the ICZ as compared to alloy V4. The hardness is however still higher than in alloy V3 for the same condition. The $0.1 \% \mathrm{Nb}$ containing steel V6 shows no softening in the CGZ. Regarding the YTR, a comparably higher minimum value of 0.57 is observed for the $\mathrm{Nb}$-free alloy in the ICZ indicating a less pronounced dual phase character. For the $0.1 \% \mathrm{Nb}$ containing steel, the YTR in the ICZ is also higher than in the previous alloys. Although these differences appear to be relatively modest, the observed effects can be attributed to the silicon alloy variation. In dual phase steel production silicon is standardly used to promote the partitioning of carbon to inter-critical austenite and, thus, to stabilize it for transformation into martensite upon quenching. This effect is based on silicon increasing the activity of carbon and also preventing the precipitation of cementite. The low-Si alloys exhibit the highest YTR values in the CGZ.

The transformation temperature $\mathrm{A}_{\mathrm{c} 1 \mathrm{P}}$ is very similar for the three $\mathrm{Nb}$-free variants of $\mathrm{V} 3, \mathrm{~V} 4$ and V6 ranging between 804 and $810^{\circ} \mathrm{C}$ whereas the $A_{3 c p}$ temperature is lower for the Mo-alloyed variants. The addition of $0.1 \% \mathrm{Nb}$ clearly shifts the $\mathrm{A}_{\mathrm{c} 1 \mathrm{p}}$ temperature upwards, particularly in combination with Mo-alloying. This is also the case for the $A_{c 3 p}$ temperature in alloys V3-d and V4-d. Remarkably, the combined alloying of Mo and $0.1 \% \mathrm{Nb}$ at reduced Si content leads to a much lower $\mathrm{A}_{\mathrm{c} 3 \mathrm{p}}$ temperature, diminishing the transition range to only $37 \mathrm{~K}$ while it is between 110 and $130 \mathrm{~K}$ for the other alloys (Figures 5 and 6).

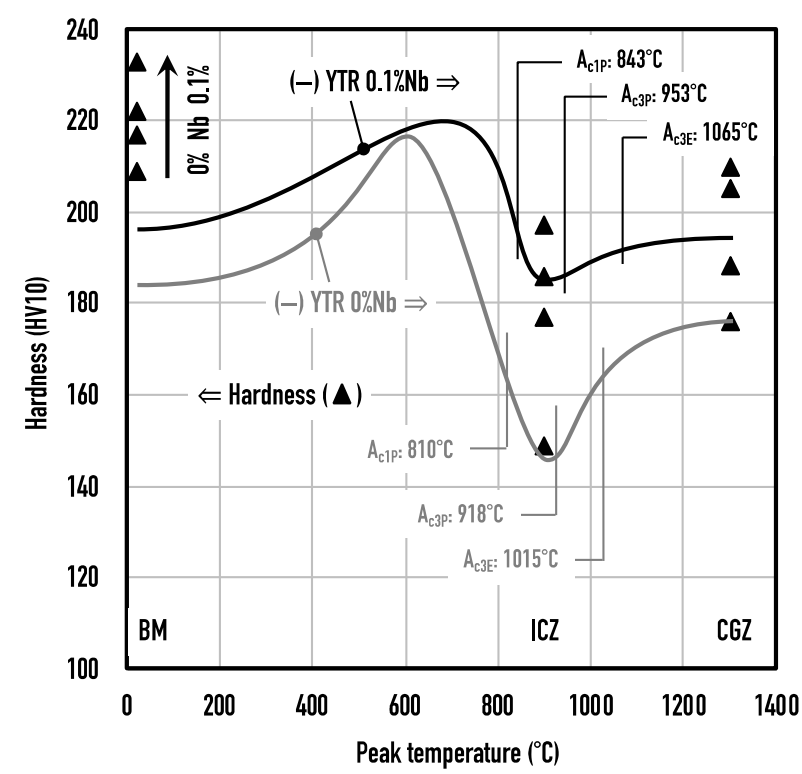

(a)

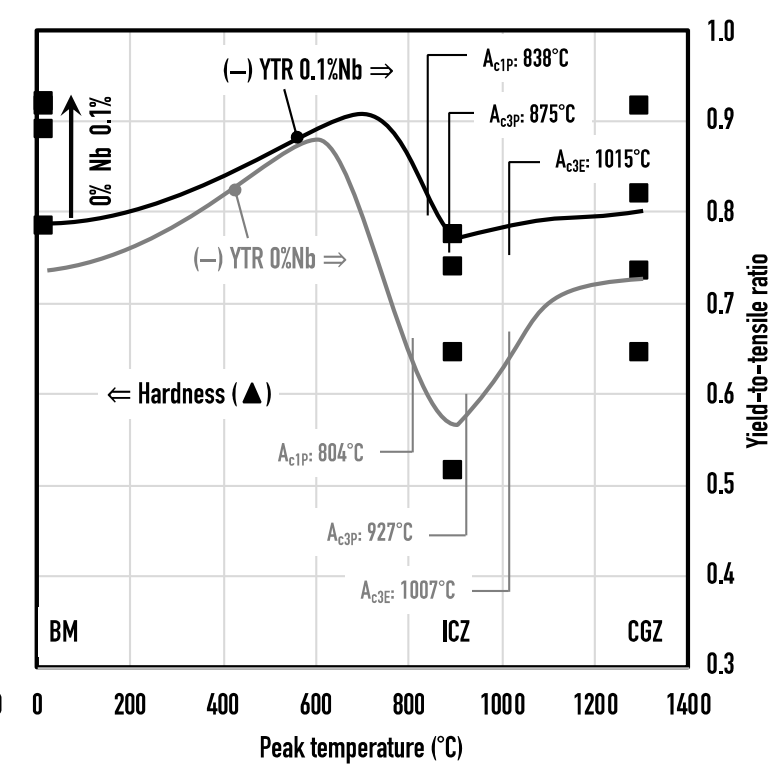

(b)

Figure 6. Evolution of hardness and yield-to-tensile ratio (YTR) in the heat-affected zone of (a) alloys V4; (b) alloys V6. Measured transformation temperatures during up-heating are indicated.

\subsection{Toughness Characteristics of HAZ Sub-Zones}

Principally, the transition from ductile to brittle fracture mode occurs in bcc-type steel when the yield strength approaches the cleavage stress level [10]. Lower temperature and higher strain rate increase the yield strength so that under impact loading conditions at a certain low temperature the yield strength exceeds the cleavage stress causing brittle failure as a consequence. Refining the 
microstructure also increases the yield strength (Hall-Petch relationship), yet the refinement has an even larger effect in terms of increasing the cleavage stress. Hence, microstructural refinement effectively lowers the DBTT. The yield strength is also increased by solid solution, precipitation and dislocation strengthening. These mechanisms have an adverse effect on the DBTT. Accordingly, for evaluating the alloy influence on the heat affected zone toughness it is most interesting to analyze the transition temperature (DBTT T50\%) as a function of the actual yield strength in the inter-critical and coarse-grained sub-zones.

Figure 7a displays the measured DBTT values as a function of the yield strength for the ICZ. The most obvious observation is that the DBTT decreases with increasing Nb content, despite strongly increasing yield strength. This can be due to pronounced grain refinement by $\mathrm{Nb}$ in the ICZ (Figure $5 b, c)$. Molybdenum alloyed variants tend to have a higher DBTT at a given yield strength level than Mo-free alloys. This discrepancy, however, diminishes with increasing $\mathrm{Nb}$ content. The Mo-alloyed variants at lower $\mathrm{Nb}$ contents contain an increased amount of carbon-rich phase, which probably is tempered martensite. The highest DBTT is observed for the steel without micro-alloy (no Ti, no $\mathrm{Nb}$ ). The low-Si Mo-alloyed variant, however, shows a low DBTT in the micro-alloy-free state.

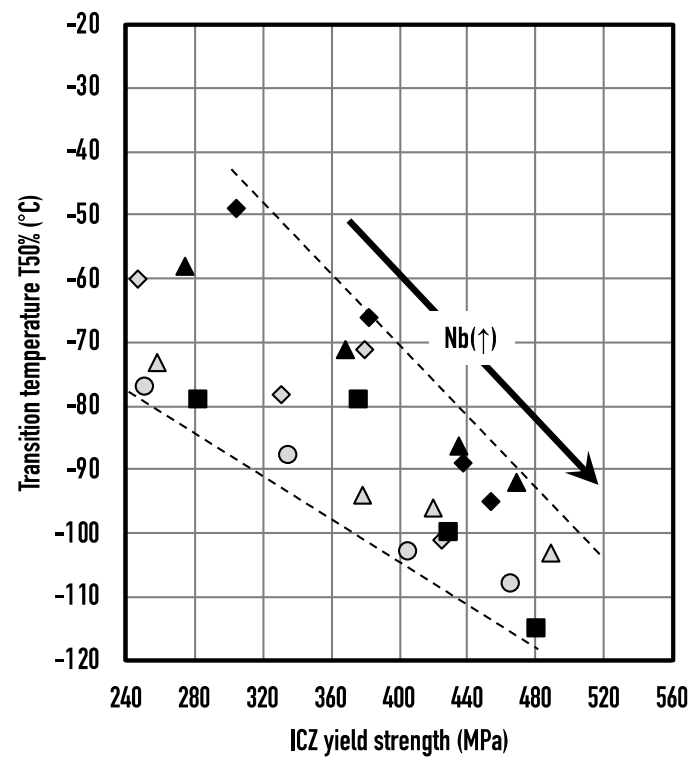

(a)

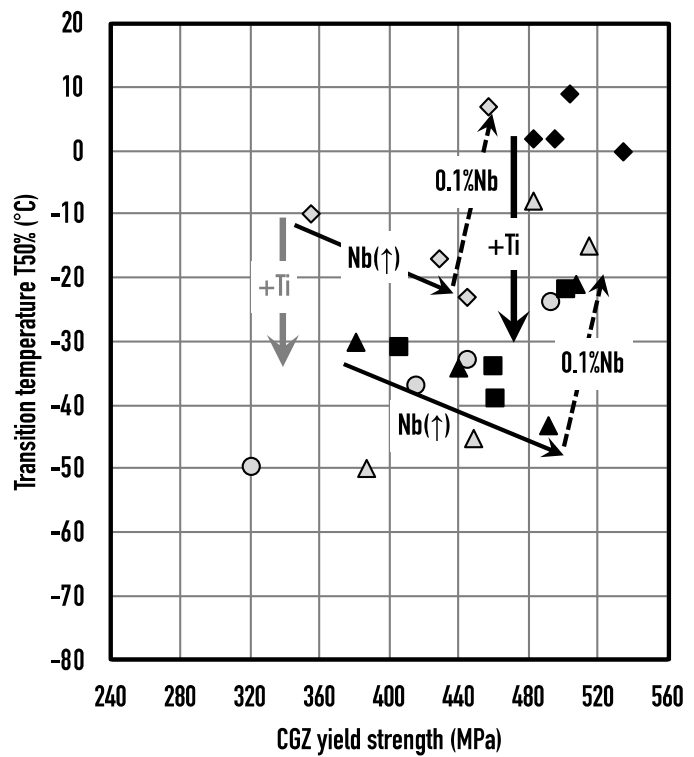

(b)

Figure 7. Ductile-to-brittle transition temperature (DBTT T50\%) determined by Charpy testing: (a) Simulated intercritcal HAZ (ICZ) with a peak temperature of $900{ }^{\circ} \mathrm{C}$; (b) simulated coarse-grained $\mathrm{HAZ}(\mathrm{CGZ})$ with a peak temperature of $1300^{\circ} \mathrm{C}$.

In the CGZ the DBTT values are generally much higher than in the ICZ for all alloy variants. This can be due to the significantly coarser grain size and the absence of ductile polygonal ferrite in the microstructure. The absence of Ti in the alloy leads to clearly higher DBTT in comparison to the Ti-alloyed variant. A significant influence of molybdenum for otherwise identical alloys cannot be detected. In several of the alloy systems, the addition of $\mathrm{Nb}$ results in a slight decrease of the DBTT, followed by a marked increase for the highest $\mathrm{Nb}$ content of $0.1 \%$. The difference in DBTT is most obvious between alloys V4 (MoNbTi) and V5 (MoNb). Comparing the microstructures of the CGZ indicates that the Ti-free alloy V5 has generally large prior austenite grain size (Figure 8), which decreases somewhat towards the highest $\mathrm{Nb}$ addition. The grain size distribution is also quite inhomogeneous. This is congruent with the high DBTT found for these alloys. On the contrary, alloy V4 has much smaller and rather homogeneous grain size. Yet, for alloy $\mathrm{V} 4$ containing $0.1 \% \mathrm{Nb}$ individual large grains are observed, which are probably the result of abnormal grain growth. The occurrence of individual large grains appears to have a significant negative influence on the DBTT. 


\section{Alloy V5 (no Ti)}
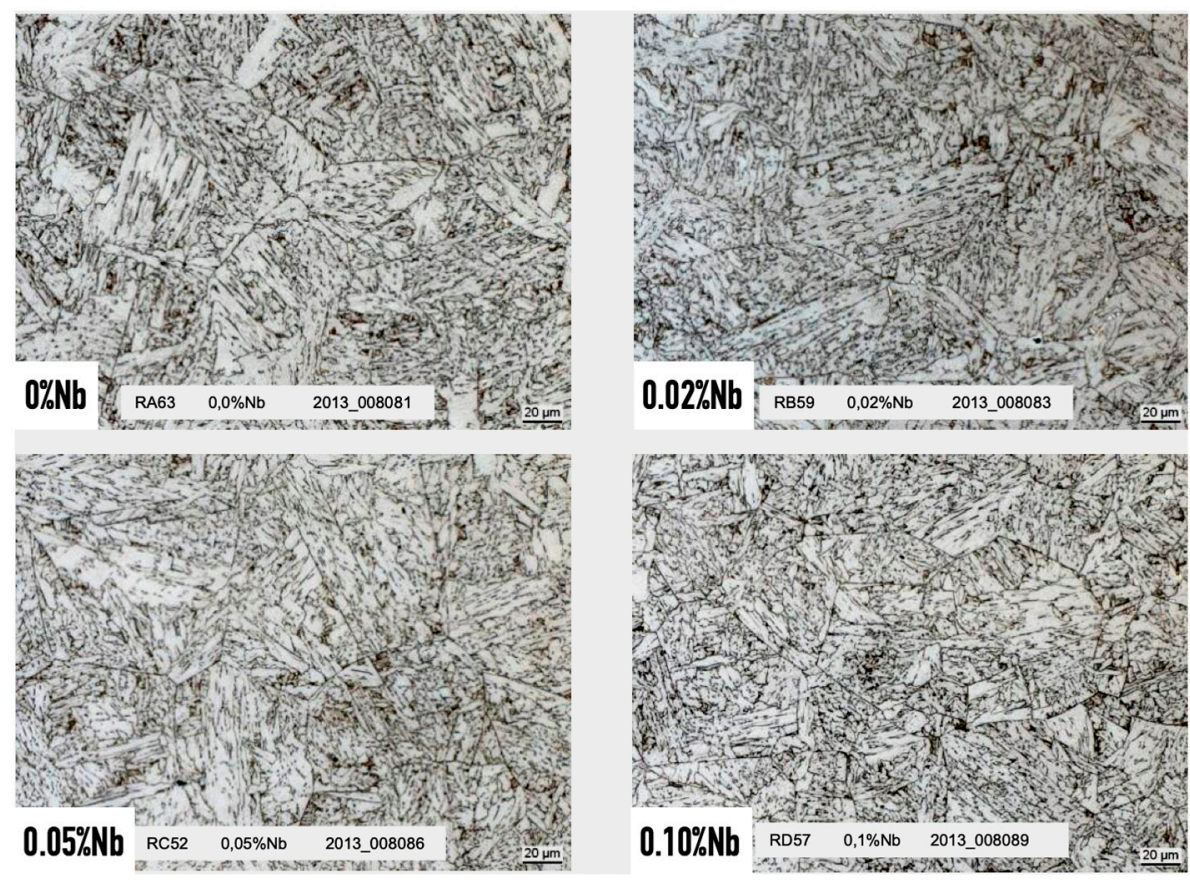

Alloy V4 (0.015\% Ti)
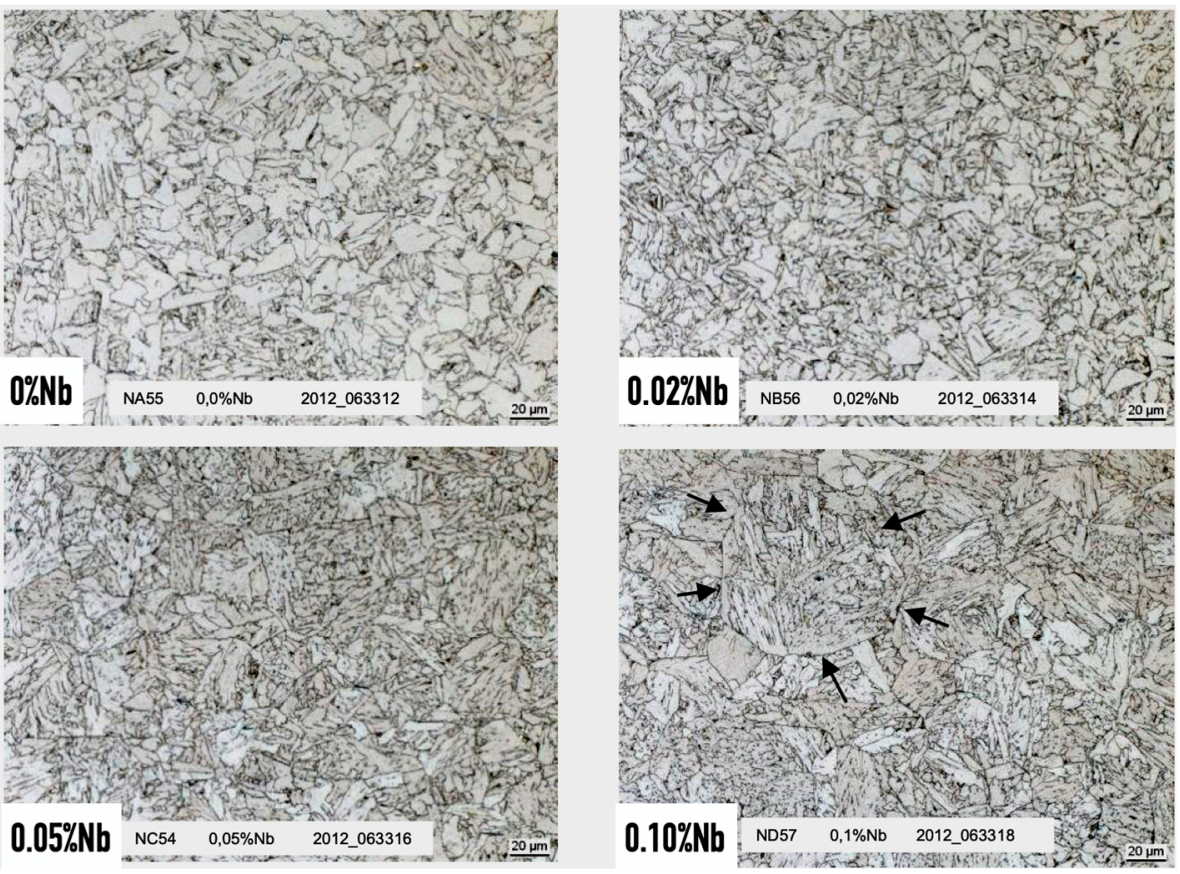

Figure 8. Effect of $\mathrm{Ti}$ and $\mathrm{Nb}$ micro-alloy addition on the microstructure in the CGZ (etching with Le Pera agent); abnormal prior austenite grain size in alloy $\mathrm{V} 4-\mathrm{d}(0.10 \% \mathrm{Nb})$ indicated by arrows.

The comparison of alloy V2-c with the corresponding industrial reference X65 steel reveals that the DBTT T50\% is approximately $30 \mathrm{~K}$ lower in the HAZ sub-zones. In the ICZ the industrial steel has a DBTT of $-130{ }^{\circ} \mathrm{C}$ as compared to $-103{ }^{\circ} \mathrm{C}$ in alloy V2-c. In the CGZ the DBTT of the industrial steel is $-65^{\circ} \mathrm{C}$ whereas for alloy $\mathrm{V} 2-\mathrm{c}$ it is $-32^{\circ} \mathrm{C}$. If this difference, being related to steel cleanness was applicable to all other laboratory alloys, one can assume that the DBTT in the CGZ of industrially produced clean steels would be generally in the sub-zero temperature range. 


\subsection{Post-Weld Heat Treatment}

During post-weld heat treatment, the strength of the material is lowered, thus, residual stresses introduced to the weld zone can relax by plastic deformation. The reduction of area during a hot-tensile test indicates how much deformation the steel can withstand without cracking. Hot-tensile testing was performed at 560 and $620^{\circ} \mathrm{C}$ with steel that was prior subjected to the CGZ simulation heat cycle. Figure 9 shows the measured reduction of area as a function of the measured hot tensile strength.

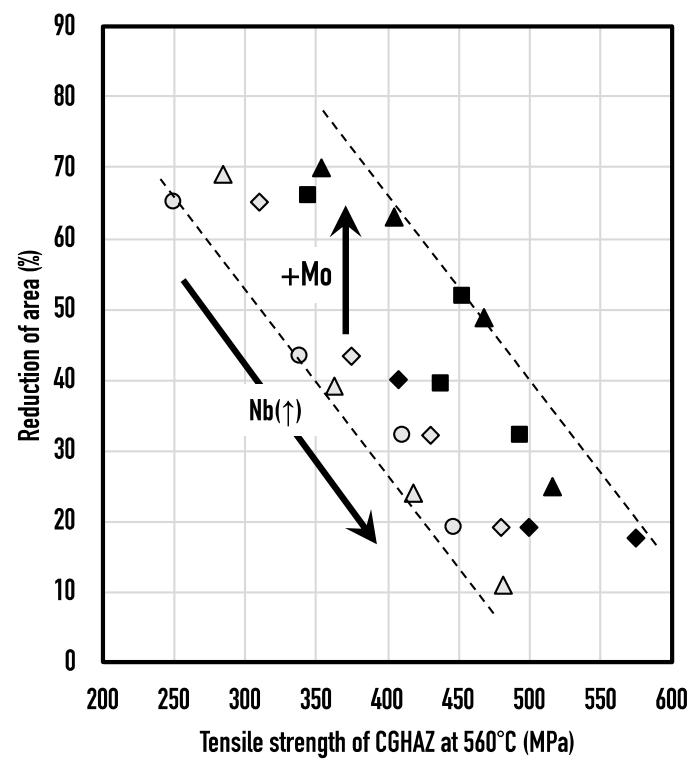

(a)

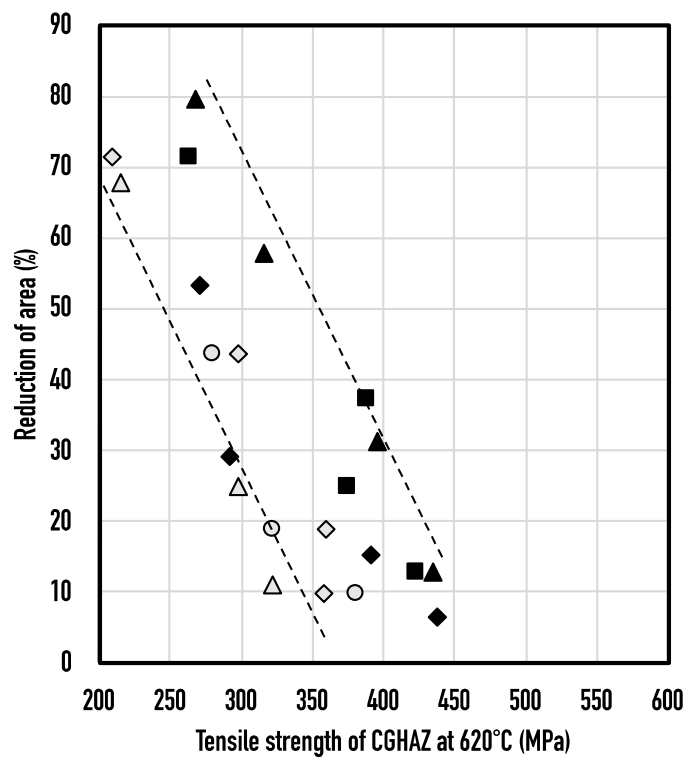

(b)

Figure 9. Reduction of area vs. hot-tensile strength of coarse-grained zone (CGZ) treated material at a test temperature of (a) $560{ }^{\circ} \mathrm{C}$ and (b) $620^{\circ} \mathrm{C}$.

Taking the original tensile strength in the CGZ as the reference, heating to $560{ }^{\circ} \mathrm{C}$ reduces the tensile strength by $150-200 \mathrm{MPa}$. When heating to $620^{\circ} \mathrm{C}$ the strength reduction is in the range of 230-330 MPa. At both temperatures, the steels alloyed with molybdenum reveal a higher strength than those without it. Increasing the niobium content systematically raises the strength. The reduction of area decreases with increasing tensile strength for all alloys at both temperatures. This decreasing effect is stronger at higher temperatures. At the same hot-tensile strength level, molybdenum alloyed steels allow a significantly higher reduction of area. The comparison of the reduction of area at $560{ }^{\circ} \mathrm{C}$ between alloy V2-c $(\mathrm{RA}=32 \%)$ and the industrial X65 steel $(\mathrm{RA}=50 \%)$ reveals again the better performance of the latter.

Finally, the toughness behavior after the post-weld heat treatment at $560^{\circ} \mathrm{C}$ for $30 \mathrm{~min}$ is analyzed in Figure 10a. One finds a strong correlation of the DBTT T50\% with the measured yield strength. The majority of the data can be fitted very well by a linear relationship indicated by the dashed line. Only the data of alloy V1 are deviating from this line. The yield strength of the higher $\mathrm{Nb}$-alloyed variants $(0.05 \% \mathrm{Nb}$ and $0.10 \% \mathrm{Nb})$ significantly increases after the heat treatment by values in the range of 50 to $175 \mathrm{MPa}$. The $\mathrm{Nb}$-free alloys show little change in yield strength. For the alloys containing $0.02 \% \mathrm{Nb}$, the strength increase is in the range of 20 to $30 \mathrm{MPa}$. In the higher $\mathrm{Nb}$-alloyed variants the DBTT increases severely by 50 to $100 \mathrm{~K}$. In the Nb-free variants, the DBTT drops by 10 to $30 \mathrm{~K}$. In alloys containing $0.02 \% \mathrm{Nb}$ the DBTT increases in the range of 10 to $30 \mathrm{~K}$. For comparing the data sets before and after heat treatment, Figure $7 \mathrm{~b}$ is re-plotted in Figure $9 \mathrm{~b}$ on the same scale as Figure $9 \mathrm{a}$. It is apparent that $\mathrm{Nb}$ precipitation moves the data points to higher strength and DBTT. For the $\mathrm{Nb}$-free alloys, tempering appears to lower the DBTT while the yield strength remains nearly unaffected. Alloying of molybdenum does not seem to have a particular influence on the toughness behavior after 
this heat treatment. Performing the same post-weld heat treatment on the CGZ of the industrial X65 steel results in a DBTT of $-55^{\circ} \mathrm{C}$ whereas in the comparable laboratory steel V2-c it is $-21^{\circ} \mathrm{C}$.

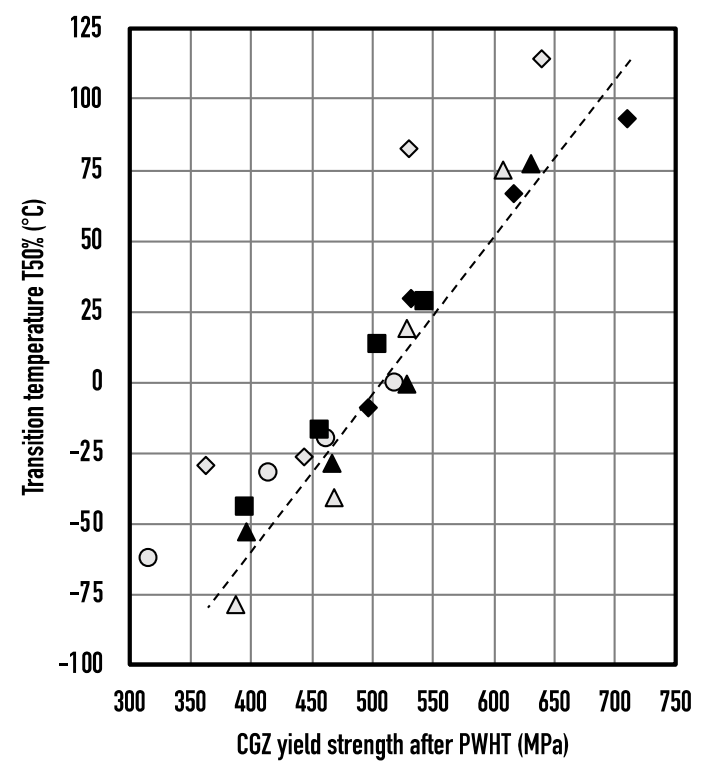

(a)

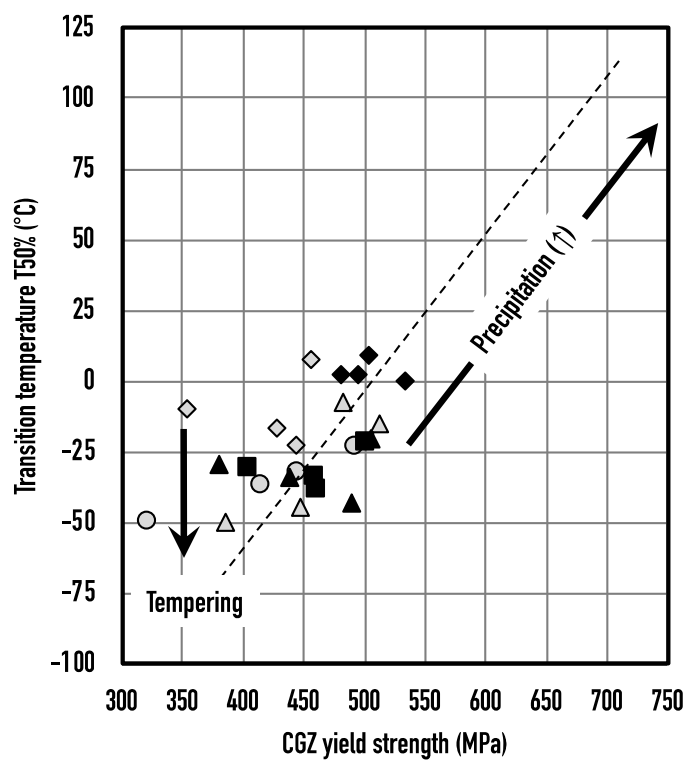

(b)

Figure 10. Influence of post-weld heat treatment (PWHT) on strength and toughness: (a) DBTT (T50\%) vs. yield strength after a relaxation treatment at $560{ }^{\circ} \mathrm{C}$ for $30 \mathrm{~min}$; (b) DBTT (T50\%) vs. yield strength before relaxation treatment (same data as Figure 7b, same trendline as Figure 9a).

\section{Discussion}

The present study has demonstrated that the influence of various alloying elements on the HAZ properties requires a careful analysis of individual metallurgical effects such as grain size, hardenability and precipitation status. In the investigated alloy variants, $\mathrm{Nb}$ and $\mathrm{Ti}$ are the elements with potential for precipitation, Mo and Mn reduce the carbon activity and increase the hardenability, and Si increases the carbon activity in austenite [11,12]. Both, Mo and $\mathrm{Nb}$ are large atoms having the tendency of segregating to grain boundaries and exerting solute drag $[13,14]$. Titanium added up to the stoichiometric ratio with respect to nitrogen contained in the steel forms very temperature-stable TiN particles, which exert grain boundary pinning in hot austenite. Niobium carbide precipitates provide also grain boundary pinning. However, $\mathrm{NbC}$ precipitates form at a lower temperature than TiN and typically niobium's precipitation is incomplete. Thus, in the interpretation of the present results, one always has to reflect on the status of niobium, which in thermodynamic equilibrium is described by established solubility equations.

The solubility of niobium carbide, where $[\mathrm{Nb}]$ and $[\mathrm{C}]$ are the alloy concentrations in mass percent, is described as a function of the absolute temperature, $\mathrm{T}$, as [15]:

$$
\log [\mathrm{Nb}][\mathrm{C}]=3.14-7753 / \mathrm{T} \text {. }
$$

Accordingly, niobium additions of $0.02,0.05$ and $0.10 \%$ to the present $0.035 \%$ carbon steel dissolve at temperatures of 960,1040 and $1120^{\circ} \mathrm{C}$, respectively. The solubility of titanium nitride carbide is similarly described as [15]:

$$
\log [\mathrm{Ti}][\mathrm{N}]=5.40-15790 / \mathrm{T} .
$$

In the present alloys, the nitrogen content $[\mathrm{N}]$ is $0.0070 \%$ so that according to Equation (2) TiN is stable beyond the upper-temperature limit of the austenite phase field for these alloys being around $1450{ }^{\circ} \mathrm{C}$. Consequently, at a peak temperature of $900^{\circ} \mathrm{C}$ simulating the inter-critical sub-zone both, $\mathrm{NbC}$ and 
TiN particles are both stable. At a peak temperature of $1300{ }^{\circ} \mathrm{C}$ simulating the coarse-grained sub-zone, however, $\mathrm{NbC}$ particles should be dissolved whereas TiN particles are still stable.

Therefore, TiN particles are available to control the austenite grain size in the CGZ simulation at $1300{ }^{\circ} \mathrm{C}$. This is indeed obvious when comparing the CGZ microstructures of Ti-free alloys (coarse-grained) with those of Ti-added alloys (fine-grained). Niobium carbide particles will fully re-dissolve during the up-heat cycle to $1300^{\circ} \mathrm{C}$. Solute $\mathrm{Nb}$ acts in the hot stage only by solute drag on austenite grain boundaries, which can contribute to finer grain size especially in combination with TiN particle pinning. This combined effect reflects an improved toughness. It is, however, also seen that for high $\mathrm{Nb}$ addition $(0.10 \%)$ individual grains can grow abnormally large, leading to a significant decrease in toughness.

In the as-rolled plates, a significant amount of niobium is expected to be in solution, out of equilibrium. This is due to the strong cooling after rolling and the low cool-stop temperature, preventing substantial precipitation of niobium as its precipitation kinetics is rather slow. Hence, any heat treatment of such an $\mathrm{Nb}$ super-saturated steel above temperatures of $500^{\circ} \mathrm{C}$ and below the equilibrium dissolution temperature given by Equation (1) will effectively lead to $\mathrm{Nb}$ precipitation. The higher the temperature is within that range, the more complete will be the precipitation. Accordingly, $\mathrm{Nb}$ precipitation can be expected for the HAZ simulations at sub-critical and inter-critical peak temperatures. Differential analysis of the tensile data allows us to estimate the contribution by $\mathrm{Nb}$ precipitation strengthening. The result of this analysis is shown for the alloys with the highest $\mathrm{Nb}$ content for the two sub-critical temperatures in Figure 11a. The precipitation strengthening is generally larger at $800{ }^{\circ} \mathrm{C}$ than at $600{ }^{\circ} \mathrm{C}$. Furthermore, the magnitude of the strengthening is with 80 to $100 \mathrm{MPa}$ rather equal in all alloys. At $600{ }^{\circ} \mathrm{C}$, the precipitation kinetics is slower and differences between the alloy systems become apparent. In alloys with an increased Mn content, the strength increase remains smaller and this effect is becoming even more pronounced when Mo is added. This can be due to the lower activity of carbon caused by Mn and Mo retarding the precipitation kinetics of $\mathrm{Nb}$. On the other hand, when $\mathrm{Si}$ is reduced as in alloy V6, precipitation appears to be accelerated. It is assumed that the lower Si content allows for the better formation of nano-cementite particles [16], which serve as a precursor for the nucleation of $\mathrm{NbC}$ [17].

In the ICZ at a $900{ }^{\circ} \mathrm{C}$ peak temperature, niobium precipitation will occur even faster. Yet it is difficult to estimate the precipitation strengthening effect since simultaneously the entire matrix microstructure changes, also affecting the strength. The very pronounced grain refinement in the ICZ microstructure of $\mathrm{Nb}$-alloyed variants certainly contributes to strength. This is caused for one part by the increased $\mathrm{A}_{\mathrm{clp}}$ temperature of the $\mathrm{Nb}$ alloyed steel vs. the $\mathrm{Nb}$-free steel, which is a solute drag effect of $\mathrm{Nb}$. The delayed partial transformation from ferrite to austenite enhances the nucleation rate for austenite grains. Secondly, the precipitation of $\mathrm{Nb}$ occurring simultaneous obstructs the growth of recrystallized ferrite and newly formed austenite grains. Re-distribution of carbon is more efficient due to shorter diffusion distances between grains in the refined ICZ microstructure. Therefore, the carbon content in newly formed austenite grains is more balanced and on average lower. This makes the formation of MA phase less likely, which is confirmed by the disappearance of the dual phase character (low YTR) that is clearly observed in the $\mathrm{Nb}$-free steel. Molybdenum increases the hardenability of carbon enriched austenite so that a higher share of the hard phase is present in Mo-alloyed steels. This reflects in lower ICZ toughness values for the Mo-alloyed steels. However, increasing Nb content offsets the Mo effect via the carbon balancing explained before. The respective carbon-reduced austenite grains have a higher martensite-start temperature and will experience severe self-tempering during the down-cooling cycle. Accordingly, toughness improves rapidly in Mo-alloyed steels with increasing $\mathrm{Nb}$ content. The reduced Si content in alloy V6-d results in a particularly low $\mathrm{A}_{\mathrm{c} 3 \mathrm{p}}$ temperature $\left(875^{\circ} \mathrm{C}\right)$ for a reason that is not yet known. As a consequence, the peak temperature of $900{ }^{\circ} \mathrm{C}$ in the ICZ heating cycle causes an almost complete austenite transformation, preventing carbon enrichment in individual grains. Therefore, the formation of hard phases despite Mo alloying is unlikely. Indeed, the toughness of steel V6-d is on the same good level as found for the best Mo-free alloys. 


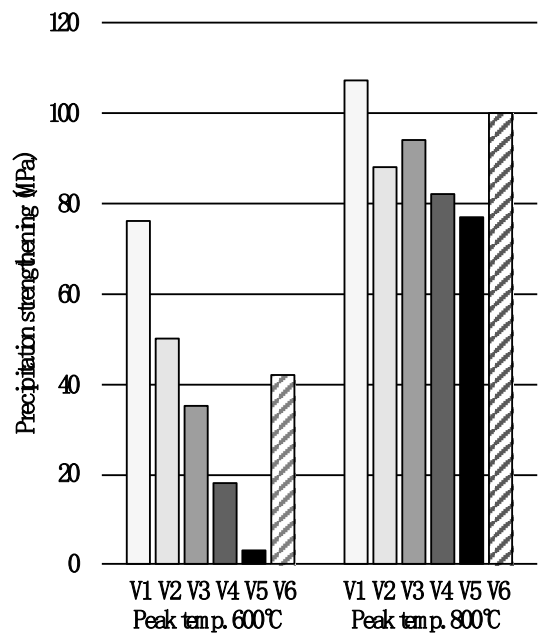

(a)

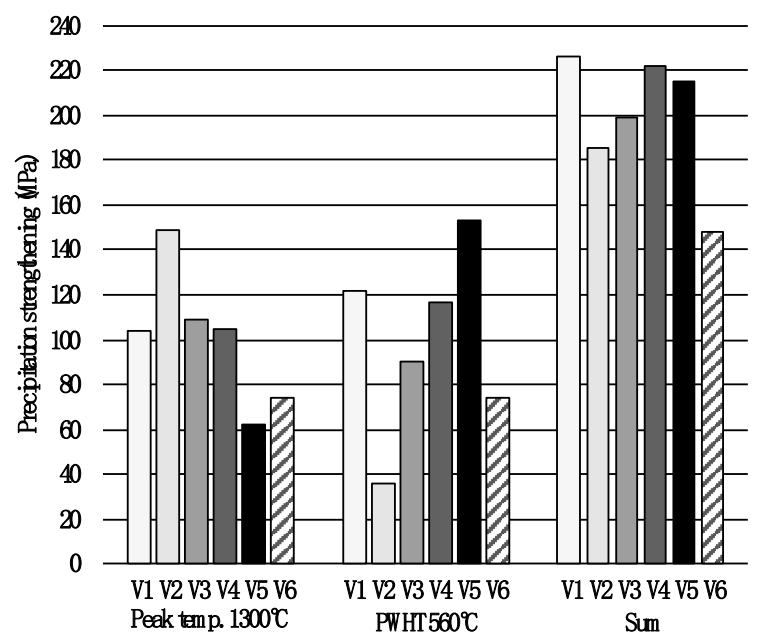

(b)

Figure 11. Precipitation strengthening effect in HAZ sub-zones for alloy variants containing $0.10 \% \mathrm{Nb}$ : (a) Sub-critical zone at peak temperatures of 600 and $800{ }^{\circ} \mathrm{C}$; (b) coarse-grained zone (peak temperature $\left.1300{ }^{\circ} \mathrm{C}\right)$, precipitation effect of PWHT $\left(560{ }^{\circ} \mathrm{C} / 30 \mathrm{~min}\right.$.) and sum of precipitation strengthening $(\mathrm{CGZ}+\mathrm{PWHT})$.

When heating up to the CGZ peak temperature of $1300^{\circ} \mathrm{C}$, all $\mathrm{NbC}$ particles present in the as-rolled plate will dissolve. The time required for dissolving such particles having typically a size below $100 \mathrm{~nm}$ is estimated to be less than one second. The TiN particles, however, remain stable. Upon down-cooling niobium's solubility decreases and $\mathrm{NbC}$ should re-precipitate. Precipitation of $\mathrm{NbC}$ does not easily occur inside the austenite grain in the absence of externally applied plastic deformation. The lattice mismatch between the austenite matrix and the $\mathrm{NbC}$ phase, both having an fcc structure, is around $25 \%$ [18]. Better nucleation conditions for precipitation are given in the austenite grain boundaries. Furthermore, niobium, as well as carbon, segregates to the grain boundary resulting in a locally much higher $[\mathrm{Nb}] \cdot[\mathrm{C}]$ solubility product. Precipitation of $\mathrm{Nb}$ should occur more efficiently during or after the phase transformation from austenite to the bcc phase. However, due to slow kinetics, it is expected to be incomplete. The precipitation strengthening effect has been estimated as shown in Figure 11b by performing a differential analysis of the tensile data of the CGZ treated steels. The magnitude of precipitation strengthening ranges between 60 and $150 \mathrm{MPa}$. The highest strengthening is found in alloy V2-d containing lower Mn and no Mo. The otherwise identical Ti-free alloy (V1-d) shows clearly lower strengthening. Likewise, this is observed when comparing alloy V4-d and V5-d, where also the Ti-free alloy exhibits clearly lower strengthening. Possibly, the larger austenite grain size in the Ti-free alloys causes a more unequal distribution of $\mathrm{Nb}$ (due to boundary segregation) and increased diffusion distances.

When applying post-weld heat treatment to the CGZ treated steels, two main metallurgical effects can be expected, being a tempering of the matrix and further precipitation of solute $\mathrm{Nb}$. The grain size will not be altered. Based on the tensile data, the softening in the matrix due to recovery processes is for all alloy systems between 40 and $50 \mathrm{MPa}$. The forthcoming additional precipitation strengthening is displayed in Figure 11b. It is largest in the Ti-free steels and generally larger in the alloys with the higher $\mathrm{Mn}$ addition and those with Mo alloying. This means that more $\mathrm{Nb}$ remained in solution after the CGZ treatment due to the slower precipitation kinetics in these particular alloys. Summing up the strengthening contributions after the CGZ and PWHT cycles results in rather similar values for all alloys with the exception of Si-reduced steel. 
The lower reduction of area observed in steels with increasing $\mathrm{Nb}$ content during the hot tensile deformation can be due to in-situ precipitation. Freshly formed precipitates may obstruct dislocations generated during the hot deformation and reduce the ductility of the matrix. It is feasible that this effect is stronger in the grain interior while the area near to the grain boundaries might be depleted from niobium as it has already precipitated after the CGZ cycle. This can lead to narrow areas in the vicinity of former austenite grain boundaries where plastic deformation will concentrate and cause rupture and a limited reduction of area. The observation that Mo alloying improves the hot ductility can be due to a retardation of in-situ precipitation and also to increased hot strength as Mo segregates to the grain boundary area. This should counteract the local concentration of plastic deformation. At the higher hot deformation temperature of $620^{\circ} \mathrm{C}$ (Figure $9 \mathrm{~b}$ ), the decrease of reduction of area with increasing $\mathrm{Nb}$ content is more pronounced since the precipitation kinetics is quicker. Yet also at this temperature, the precipitation retarding effect of Mo is evident.

The understanding that in-situ precipitation of $\mathrm{NbC}$ during hot deformation is the main cause for reduced ductility allows designing practical solutions to alleviate problems when post-weld heat treating steel with higher $\mathrm{Nb}$ addition. Firstly, the post-weld heat treatment can be done at the lower side of the typical temperature range of 500 to $600{ }^{\circ} \mathrm{C}$, preferably below $550{ }^{\circ} \mathrm{C}$, slowing down the kinetics of in-situ precipitation. Secondly, molybdenum should be co-alloyed to niobium for additionally retarding the precipitation kinetics and stabilizing the niobium-depleted areas in the vicinity of grain boundaries. Titanium micro-alloying restricts the CGZ grain size, thus, providing improved toughness. Thirdly, welding should be executed using the multi-pass technique in a way that the CGZ of an earlier pass obtains sufficient tempering by a subsequent weld pass. In this way, precipitation is already being anticipated in a large part of the CGZ rendering less solute $\mathrm{Nb}$ for in-situ precipitation during PWHT. Since PWHT is typically applied to components fabricated from thick plate gages, multi-pass welding is usually applied. The parameters of the individual passes should be optimized to allow a maximum tempering effect on previous passes.

\section{Conclusions}

Increasing addition of niobium raises yield strength and improves toughness simultaneously in the as-rolled state of the considered extra-low carbon steels. The combined addition of molybdenum and niobium provides the highest strength fulfilling the requirements for grade $\mathrm{X} 80$.

Regarding the inter-critical heat-affected zone, niobium-free steels have the lowest yield strength and toughness. These steels exhibit a low yield-to-tensile ratio, which is caused by a fraction of martensite islands dispersed in recrystallized ferrite. Adding niobium in increasing amounts raises the yield strength as well as the yield-to-tensile ratio. The recrystallized ferrite grain size is being severely refined and martensite formation is being suppressed. Consequently, ICZ toughness is improving with increasing niobium content.

Molybdenum addition increases the amount of hard phase in the inter-critical heat-affected zone leading to a decrease of ICZ toughness. The hard phase appears predominantly as tempered martensite. At higher niobium additions this toughness-reducing effect of molybdenum is being diminished. Lowering the silicon content further reduces the formation of hard phases.

Regarding the coarse-grained heat affected zone, titanium-free steels show low CGZ toughness due to excessive grain coarsening. A small addition of titanium, typically in near-stoichiometric ratio to residual nitrogen present in the steel, counteracts pronounced grain coarsening. Increasing niobium content can further improve toughness in combination with titanium. At the highest niobium addition, however, individual grains showed abnormal coarsening in several alloys. The mechanism for this abnormal grain growth must be investigated in more detail. Increasing niobium content leads also to more pronounced precipitation strengthening reducing CGZ toughness. Thus, the actual toughness performance of the coarse-grained heat affected zone is controlled by the counteracting effects of grain refinement and precipitation. 
Toughness in the coarse-grained heat affected zone after post-weld heat treatment is controlled by the degree of in-situ precipitation of niobium that was prior dissolved during the CGZ heat cycle. The potential of in-situ precipitation increases naturally with the niobium content in the steel. However, by anticipating or delaying in-situ precipitation, PWHT embrittlement can be reduced to an acceptable level. This requires careful consideration of the integral alloy concept, the selected PWHT temperature and an appropriate multi-pass welding schedule. Molybdenum, particularly, was found to improve hot ductility, which helps to avoid stress relaxation cracking.

Author Contributions: H.M. evaluated and analyzed the data and wrote the paper. All interpretations of the observed effects reflect H.M.'s personal opinion.

Funding: This work was funded in part by the International Molybdenum Association (IMOA), London, UK and by Companhia Brasileira de Metalurgia e Mineraçao (CBMM), Sao Paulo, Brazil.

Acknowledgments: The author sincerely acknowledges the experimental work and data preparation by Franz Mayrhofer, Rupert Egger and Irina Eisheuer of Voestalpine Grobblech GmbH.

Conflicts of Interest: The author declares no conflict of interest. The funders had no role in the design of the study; in the collection, analyses, or interpretation of data; in the writing of the manuscript, or in the decision to publish the results.

\section{References}

1. Gray, J.M. Application of Niobium-Molybdenum strengthening mechanisms in high strength linepipe steels. In Fundamentals and Applications of Mo and Nb Alloying in High Performance Steels; Mohrbacher, H., Ed.; TMS: Pittsburgh, PA, USA, 2014; Volume 1, pp. 121-134.

2. Mohrbacher, H.; Spöttl, M.; Paegle, J. Innovative manufacturing technology enabling light weighting with steel in commercial vehicles. Adv. Manuf. 2015, 3, 3-18. [CrossRef]

3. Hulka, K.; Gray, J.M. High Temperature Processing of Line Pipe Steels. In Niobium Science \& Technology, Proceedings of the International Symposium Niobium, Orlando, FL, USA, 2-5 December 2001; TMS: Pittsburgh, PA, USA, USA, 2001; pp. 587-612.

4. Gray, J.M. Weldability of Niobium Containing HSLA Steel. WRC Bull. 1976, 213, 1-19.

5. Aronson, A.H. The Weldability of Columbium-bearing High Strength Low Alloy Steel. Weld. J. 1966, 45, S266.

6. Kirkwood, P. Niobium and Heat Affected Zone Mythology. In Proceedings of the International Seminar on Welding of High Strength Pipeline Steels, Araxá, Brazil, 27-30 November 2011; CBMM: Araxá, Brazil, 2011; pp. 23-64.

7. Bersch, B.; Kaup, K. Effect of Niobium on the Welding Behaviour of Thermomechanically Rolled Steels. 3R Int. 1983, 22, 484-492.

8. Wiebe, J.; Scheller, W.; Stallybrass, C. HAZ Properties of Nb Microalloyed High Strength Pipeline Steels. Steel Res. Int. 2017. [CrossRef]

9. De Meester, B. The Weldability of Modern Structural TMCP Steels. ISIJ Int. 1997, 37, 537-551. [CrossRef]

10. Morris, J.W. On the Ductile-Brittle Transition in Lath Martensitic Steel. ISIJ Int. 2011, 51, 1569-1575. [CrossRef]

11. Eckstein, H.J.; Fennert, M.; Ohser, J. Application of thermodynamic computations to the solution behaviour of niobium and vanadium carbonitrides. Steel Res. 1993, 64, 143-147. [CrossRef]

12. Koyama, S.; Ishii, T.; Narita, K. Effects of $\mathrm{Mn}, \mathrm{Si}, \mathrm{Cr}$ and $\mathrm{Ni}$ on the Solution and Precipitation of Niobium Carbide in Iron Austenite. J. Jpn. Inst. Met. 1971, 35, 1089-1094. [CrossRef]

13. Hoerner, M.; Speer, J.; Eberhart, M. Comparison of Ab-initio Solute-Boundary Binding Energies and Experimental Recrystallization Data in Austenite for Solute $\mathrm{Nb}$ and Other Elements. ISIJ Int. 2017, 57, 1847-1850. [CrossRef]

14. Raabe, D.; Herbig, M.; Sandlöbes, S.; Li, Y.; Tytko, D.; Kuzmina, M.; Ponge, D.; Choi, P.-P. Grain boundary segregation engineering in metallic alloys: A pathway to the design of interface. Curr. Opin. Solid State Mater. Sci. 2014, 18, 253-261. [CrossRef]

15. Kunze, J. Nitrogen and Carbon in Iron and Steel Thermodynamics; Wiley-VCH Verlag GmbH: Weinheim, Germany, 1990; pp. 178-206.

16. Kozeschnik, E.; Bhadeshia, H.K.D.H. Influence of silicon on cementite precipitation in steel. Mater. Sci. Technol. 2008, 24, 343-347. [CrossRef] 
17. Hin, C.; Bréchet, Y.; Maugis, P.; Soisson, F. Kinetics of heterogeneous dislocation precipitation of $\mathrm{NbC}$ in alpha-iron. Acta Mater. 2008, 56, 5535-5543. [CrossRef]

18. Farjami, S.; Kubo, H. Elastic Energy Analysis of Carbide and Nitride-Type Precipitates in an Fe-Mn-Si-Cr Shape Memory Alloy. Mater. Trans. 2006, 47, 564-570. [CrossRef] 